\title{
Successful management of a sporadic pancreatic insulinoma by endoscopic ultrasound-guided radio- frequency ablation
}
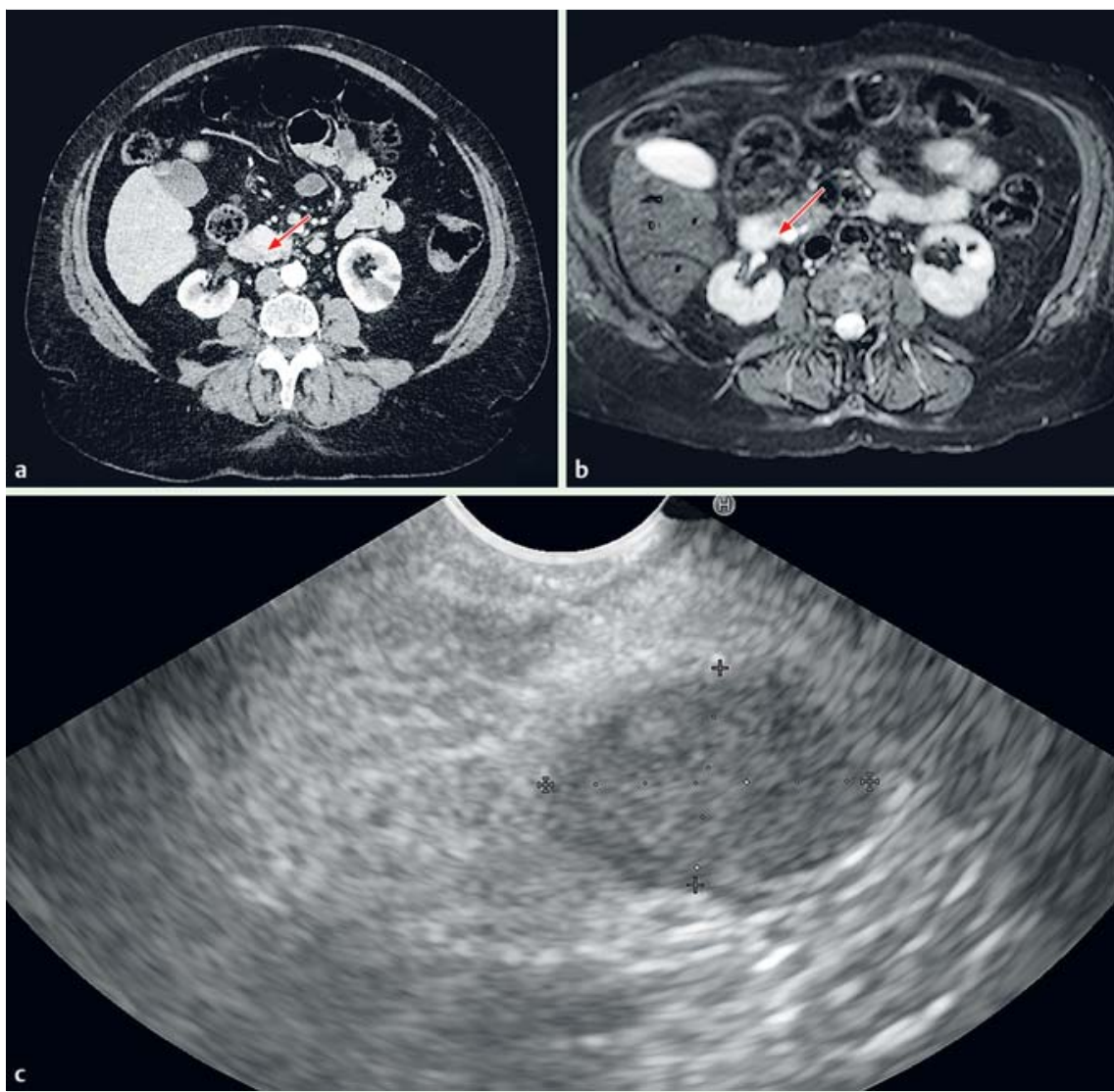

Fig. 1 Pretreatment imaging showing: a on a computed tomography (CT) scan, an 18-mm round lesion with arterial enhancement, characteristic of a pancreatic neuroendocrine tumor; $\mathbf{b}$ the lesion on magnetic resonance imaging (MRI); c a hypoechoic circular lesion on endoscopic ultrasound (EUS).

Table 1 Summary of the three endoscopic ultrasound-guided radiofrequency ablation (EUS-RFA) procedures performed in a patient with a pancreatic neuroendocrine tumor.

\begin{tabular}{|c|c|c|c|c|c|}
\hline $\begin{array}{l}\text { Procedure } \\
\text { number }\end{array}$ & $\begin{array}{l}\text { Number of } \\
\text { ablations }\end{array}$ & $\begin{array}{l}\text { Individual } \\
\text { ablation time, } \\
\text { seconds }\end{array}$ & $\begin{array}{l}\text { Procedure time - } \\
\text { first ablation to } \\
\text { last, minutes }\end{array}$ & $\begin{array}{l}10 \% \text { dextrose } \\
\text { requirements, } \\
\mathrm{mL} / \text { hour }\end{array}$ & $\begin{array}{l}\text { Tumor } \\
\text { volume, } \\
\mathrm{cm}^{3}\end{array}$ \\
\hline 1 & 3 & 120 & 6 & $\begin{array}{l}100 \\
\text { (pretreatment) }\end{array}$ & 2.14 \\
\hline 2 & 8 & 90 & 33 & $\begin{array}{l}15 \\
\text { (post-treatment) }\end{array}$ & 0.52 \\
\hline 3 & 14 & 90 & 55 & $\begin{array}{l}0 \\
\text { (post-treatment) }\end{array}$ & 0 \\
\hline
\end{tabular}

A 70-year-old woman presented with an 18-month history of recurrent episodes of dizziness that were alleviated by sugary drinks. During one of these episodes, a low blood glucose of $1.6 \mathrm{mmol} / \mathrm{L}$ was noted. Her past medical history included atrial fibrillation and severe chronic ob- structive pulmonary disease (COPD), necessitating long-term oxygen therapy. Given the high index of suspicion of spontaneous hypoglycemia, further investigations commenced with a supervised 72-hour fast. This confirmed symptomatic hyperinsulinemic hypoglycemia: serum
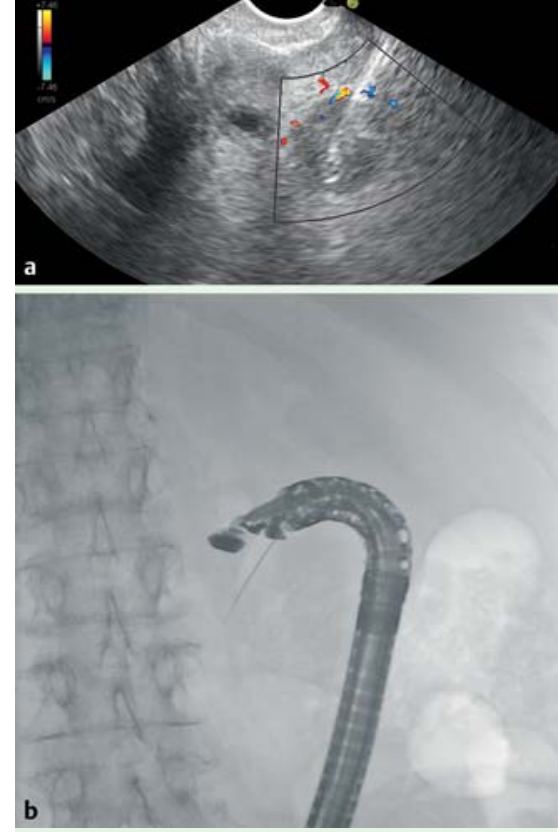

Fig. 2 a The Habib endoscopic ultrasoundguided radiofrequency ablation (EUS-RFA) probe positioned within the insulinoma on: a EUS imaging (note also the 19G fine needle aspiration [FNA] needle at the edge of the insulinoma); b fluoroscopic imaging.

glucose of $1.8 \mathrm{mmol} / \mathrm{L}$ (normal range 37.8), insulin 17.3 milliunits/L, and C-peptide $2418 \mathrm{pmol} / \mathrm{L}$ at 34 hours. The serum sulphonylurea screen was negative. A computed tomography (CT) scan revealed an 18-mm enhancing lesion in the uncinate consistent with a neuroendocrine tumor and this was confirmed by an endoscopic ultrasound with fine needle aspiration (EUS-FNA) ( $\bullet$ Fig. 1 ).

The patient was prescribed diazoxide $50 \mathrm{mg}$, but this had to be discontinued because of acute fluid retention. She remained symptomatic but was a poor surgical candidate so was commenced on a low glycemic-index diet and octreotide. This was unsuccessful, so she remained on a continuous infusion of $10 \%$ dextrose. The patient was therefore referred for EUS-guided radiofrequency ablation (RFA).

RFA causes thermal coagulative necrosis through the administration of a high frequency current. The technique is now 

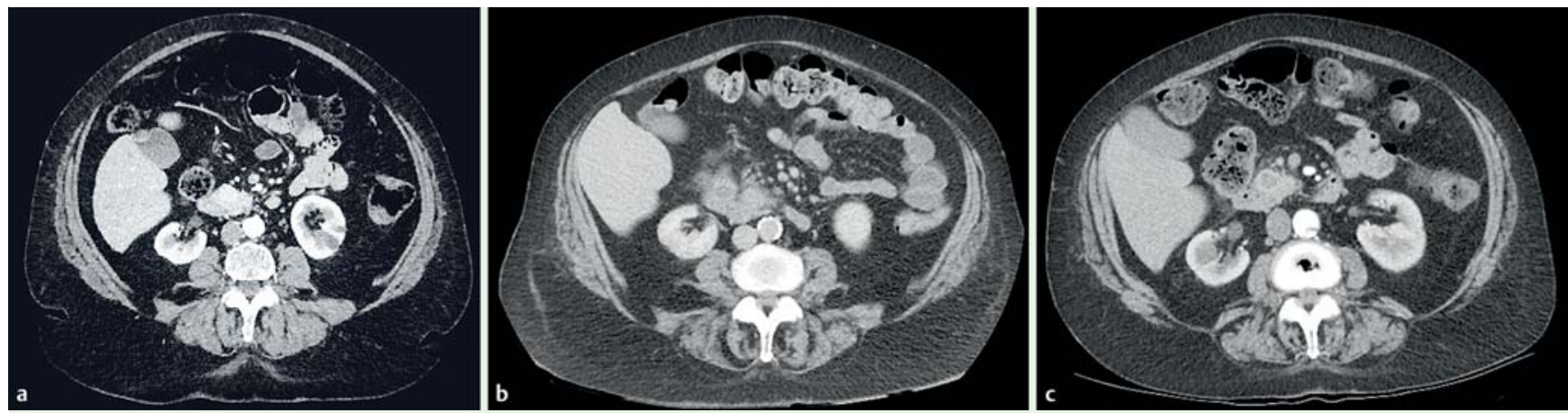

Fig. 3 Computed tomography (CT) images showing the appearance: a pretreatment, with an 18-mm round arterial enhancing lesion; $\mathbf{b}$ after the first endoscopic ultrasound-guided radiofrequency (EUS-RFA) treatment, showing an area of central low density, representing necrosis; $\mathbf{c}$ after the final EUS-RFA treatment, showing a larger area of central low density, representing necrosis.

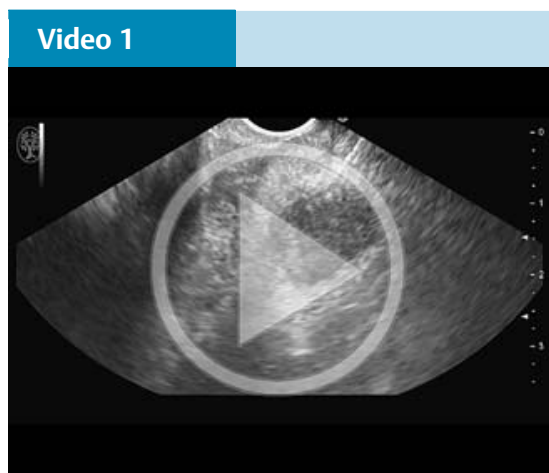

The three endoscopic ultrasound-guided radiofrequency ablation (EUS-RFA) procedures showing the withdrawal of the fine needle aspiration (FNA) needle and activation of the RFA probe.

part of standard therapy for several tumors including hepatocellular carcinoma [1]. Recently a new monopolar RFA probe has been developed that can be placed down the working channel of a linear echoendoscope (Habib EUS-RFA catheter; Emcision Ltd, London, UK), enabling RFA to be administered under EUS guidance. To date it has been used in the management of two neuroendocrine tumors worldwide and in both cases the tumor decreased in size [2].

EUS-guided RFA was undertaken as a series of three treatments, each 1 week apart ( Table 1, Video 1). The procedures were performed with the patient under deep propofol sedation or general anesthesia. During the first procedure, three applications of RFA were administered at $10 \mathrm{~W}$ and were directed into the central part of the tumor ( $\bullet$ Fig.2). After the procedure, the patient's glucose requirements initially decreased but increased back to pretreatment levels within 24 hours. A post-treatment CT scan on day 1 showed no complications and some central necrosis within the tumor ( $\mathbf{F i g . 3}$ ).
During the second treatment the probe was placed within the tumor in two different planes and eight sequential treatments were administered at $10 \mathrm{~W}$. The patient's glucose requirements immediately halved and repeat imaging showed a larger area of central necrosis, but the edge of the tumor was unchanged. On the third occasion, 14 sequential treatments were administered. After 10 treatments in three planes, a contrast-harmonic EUS with SonoVue (sulfur hexafluoride microbubbles; Bracco UL Ltd., High Wycombe, UK) was performed and revealed tumor remaining within the distal wall, so four further RFA treatments were directed at this area $(\bullet$ Fig. 3c). After the final EUS-RFA treatment, the patient's glucose requirements ceased and octreotide therapy was withdrawn ( $\bullet$ Table 1$)$. Before the patient was discharged, a 72hour supervised fast was completed without hypoglycemia, consistent with biochemical remission. A post-procedural CT showed that the lesion had been almost completely replaced by necrotic tissue and $a^{68}$ gallium dotatate positron emission tomography (PET)-CT scan showed that the abnormal uptake within the uncinate process had resolved. The patient was discharged home and remained well and asymptomatic after 10 months.

This case supports the use of EUS-RFA in the management of patients with functional pancreatic neuroendocrine tumors who have failed multiple medical therapies and cannot undergo surgery because of comorbidities. Long-term outcomes and further experience is required but this novel approach should be considered for selected patients.

\section{Endoscopy_UCTN_Code_TTT_1AS_2AD}

\section{Competing interests: None}

Julian A. Waung' , Jeannie F. Todd ${ }^{\text {, }}$ Margaret G. Keane ${ }^{2}$, Stephen P. Pereira $^{2}$

${ }^{1}$ Imperial Centre for Endocrinology, Hammersmith Hospital, Imperial College Healthcare NHS Trust, London, UK

2 UCL Institute for Liver and Digestive Health, University College London, London, UK

\section{Acknowledgments}

This work was supported by the National Institute for Health Research UCL Hospitals Biomedical Research Centre.

\section{References}

1 Llovet JM, Bru C, Bruix J. Prognosis of hepatocellular carcinoma: the BCLC staging classification. Semin Liver Dis 1999; 19: 329-338

2 Pai M, Senturk H, Lakhtakia $S$ et al. Endoscopic ultrasound guided radiofrequency ablation (EUS-RFA) for cystic neoplasms and neuroendocrine tumours of the pancreas. Gastrointest Endosc 2013; 77: AB143-AB144

\section{Bibliography}

Dol http://dx.doi.org/

10.1055/s-0042-104650

Endoscopy 2016; 48: E144-E145

(c) Georg Thieme Verlag KG

Stuttgart · New York

ISSN 0013-726X

Corresponding author

\section{Stephen Pereira, MD, PhD}

UCL Institute for Liver and Digestive Health

Royal Free Campus

Pond Street

London

NW3 2QG

UK

stephen.pereira@ucl.ac.uk 